\title{
Gamma Knife Radiosurgery for Pediatric Arteriovenous Malformations: A Canadian Experience
}

\author{
Fred A. Zeiler, Maciej K. Janik, Patrick J. McDonald, Anthony M. Kaufmann, \\ Derek Fewer, Jim Butler, Garry Schroeder, Michael West
}

\begin{abstract}
Background: Gamma Knife (GK) radiosurgery for pediatric arteriovenous malformations (AVM) of the brain presents a non-invasive treatment option. We report our institutional experience with GK for pediatric AVMs. Methods: We performed a retrospective review of all pediatric patients treated with GK for cerebral AVMs at our institution from November 2003 up to and including September 2014. Patient demographics, AVM characteristics, treatment parameters and AVM responses were recorded. Results: Nineteen patients were treated, with 4 lost to follow-up. The mean age was 14.2 years (range. 7-18 years), with 10 being males (52.6\%). The mean AVM diameter and volume were $2.68 \mathrm{~cm}$ and $3.10 \mathrm{~cm}^{3}$ respectively. The mean Spetzler-Martin (SM) and Pollock grades of the treated AVMs were 2.4 and 0.99 respectively. The mean follow-up was 62 months. All AVMs treated demonstrated a response on follow-up imaging. Nine of 15 (60.0\%) patients displayed obliteration of their AVMs. Nine of 11 patients with a minimum of 3 years follow-up $(81.8 \%)$ displayed obliteration, with SM and Pollock grades correlating to the chance of obliteration in this group. Two patients developed post-GK edema requiring short course dexamethasone therapy. No other major complications occurred. No permanent complications occurred. Conclusions: GK radiosurgery for pediatric AVMs offers a safe and effective treatment option, with low permanent complication rates during early follow-up.
\end{abstract}

RÉSUMÉ: Expérience canadienne de la radiochirurgie par scalpel gamma utilisée dans le traitement de malformations artérioveineuses chez l'enfant. Contexte : La radiochirurgie par scalpel gamma (SG) constitue une option de traitement non-invasive pour les malformations artérioveineuses (MAV) chez l'enfant. Nous rapportons notre expérience de l'utilisation du SG pour traiter des MAV chez des enfants dans notre institution. Méthode : Nous avons effectué une revue rétrospective de tous les dossiers de patients d'âge pédiatrique traités par SG pour une MAV dans notre institution entre novembre 2003 et septembre 2014 inclusivement. Nous avons relevé les données démographiques des patients, les caractéristiques des MAV, les paramètres de traitement et les résultats obtenus. Résultats : Dix-neuf patients ont été traités, dont 4 ont été perdus au suivi. L'âge moyen des patients était de 14,2 ans (écart de 7 à 18 ans) et 10 d'entre eux étaient des garçons (52,6\%). Le diamètre moyen de la MAV et son volume étaient de 2,68 cm et 3,10 cm3 respectivement. Le grade moyen à l'échelle Spetzler-Martin (SM) et à l'échelle Pollock des MAV traitées étaient de 2,4 et 0,99 respectivement. Le suivi moyen était de 62 mois. À l'imagerie, une réponse au traitement était évidente au niveau de toutes les MAV traitées. Chez 9 patients sur 15 (60\%) la MAV était oblitérée. Chez 9 patients sur 11, après un suivi minimum de 3 ans $(81,8 \%)$, l'oblitération a été constatée avec des grades de SM et de Pollock compatibles avec une oblitération chez ce groupe de patients. Deux patients ont présenté de l'œdème après la radiochirurgie par SG nécessitant un traitement de courte durée par la dexaméthasone. Aucune autre complication majeure n'a été constatée et aucune complication permanente n'est survenue. Conclusions : La radiochirurgie par SG chez les enfants atteints de MAV constitue une option de traitement sûre et efficace comportant un faible taux de complications permanentes tôt au cours du suivi.

Keywords: Cerebrovascular disease, CNS malformations, neurosurgery - pediatric, neurosurgery - vascular, pediatrics, radiation oncology, radiosurgery, stereotactic

doi:10.1017/cjn.2015.267

Can J Neurol Sci. 2016; 43: 82-86

Pediatric arteriovenous malformations (AVM) typically present with a higher incidence of intracerebral hemorrhage (ICH)/intraventricular hemorrhage (IVH) than their adult counterparts, and carry higher mortality rates with hemorrhage. ${ }^{1-3}$ Debate exists around the most appropriate treatment option for AVMs in both the pediatric and adult populations. Available treatment options include: microsurgical resection, endovascular embolization, stereotactic radiosurgery (SRS), and combinations of these approaches. ${ }^{1-4}$ Microsurgical resection, considered the gold standard, is typically reserved for small superficially located lesions without deep venous drainage, with obliteration and morbidity/mortality rates in children reported around $90 \%$ and 3 to $5 \%$, respectively. ${ }^{4}$
The use of endovascular embolization of AVMs in pediatric patients has been associated with poor obliteration rates; typically below $20 \%$, with mobidity/mortality rates upwards of $11.8 \%$. $^{1,5}$ With the advent of SRS, the treatment of all cerebral AVMs has

From the Section of Neurosurgery (FAZ, PJM, AMK, DF, MW); Undergraduate Medicine (MKJ), Medical University of Warsaw, Warsaw, Poland; Section of Radiation Oncology (JB, GS), University of Manitoba, Winnipeg, Manitoba, Canada.

Received November 13, 2015. Final Revisions Submitted April 1, 2015. Correspondence to: Frederick A. Zeiler, Neurosurgery, Health Sciences Center, University of Manitoba, GB-134, 820 Sherbrook Street, Winnipeg, Manitoba, R3A1R9. Email: umzeiler@cc.umanitoba.ca 
changed drastically in the last 20 years, offering a safer option for deep seated and eloquently located lesions.

Small numbers of retrospective case series have appeared in the literature over the last ten years reporting AVM response to Gamma Knife (GK) in the pediatric population. ${ }^{6-12}$ Obliteration rates for pediatric AVMs with GK SRS range from $65 \%^{7}$ to $82.7 \%^{6}$ at three years follow-up. Reported complication rates range from $1.5 \%$ to $15.5 \% .^{9}$ The majority of these complications are reported as post-GK hemorrhage, that are well within the expected natural history of these lesions.

Within this study we retrospectively reviewed our institutional series of pediatric AVMs treated with GK in order to determine our obliteration and complication rates.

\section{MeTHODS}

\section{Study Design}

Our study population of interest was all pediatric patients treated with GK for AVMs at our institution between November 2003 (initiation of GK in Winnipeg) up to and including September 2014. We performed a retrospective review of our institutional GK database in order to identify those patients treated for AVMs. We then selected those patients 18 years of age and under treated for AVMs with GK. This age range was deemed to represent the "pediatric" population.

\section{Data Acquisition}

Two independent reviewers reviewed the patient records and GK treatment plans for all the patients meeting the inclusion criteria, as defined above. Nineteen patients were identified. The following data was recorded: patient demographics, presenting features, AVM characteristics, Spetzler-Martin grade, ${ }^{13}$ Pollock radiosurgery grade, ${ }^{14,15}$ treatment response, timing of response, and complications. All data was stored within a secure electronic database.

\section{Statistical Analysis}

Detailed statistical analysis was not performed given the small number of patients identified. Simple descriptive statistics were presented, including mean and median values.

\section{Ethics}

Local research health ethics approval was obtained for this study.

\section{RESUlTS}

\section{Patient Demographics and AVM Characteristics}

We identified 19 pediatric patients treated with GK for AVMs between November 2003 and September 2014. The average age at presentation/treatment with GK was 14.2 years (range: 7-18 years; median: 15.0 years), with 10 male $(52.6 \%)$ and 9 female patients (47.4\%). Treatments prior to GK at our institution included: attempted surgical resection followed by embolization in one patient $(5.35 \%)$, attempted embolization alone in patients $(10.5 \%)$ and GK at a different center in two patients (10.5\%). The average time from attempted embolization to GK was 12.3 months (range: 2 to 24 months). The remaining 14 patients (73.7\%) had not received any other treatment for their AVMs prior to GK at our institution. The mean follow up post-GK was 62 months (range: 13 to 118 months; median: 51 months). Follow-up clinic visits were conducted at six to eight weeks post treatment. Imaging was conducted at one, two, and three years post treatment with magnetic resonance imaging (MRI) or computed tomographic angiography (CTA). Initially, when either MRI or CTA demonstrated the absence of an AVM nidus, subsequent digital subtraction angiography (DSA) was conducted in order to determine AVM patency or obliteration. However, more recently we have relied on MRI and/or CTA alone to demonstrate obliteration, in the absence of the use of DSA. Avoiding the use of DSA was based on the literature demonstrating the efficacy of MRI and its ability to predict AVM patency. ${ }^{12}$ A summary of patient demographics can be seen in Table 1 .

Four patients $(21.1 \%)$ were lost to follow-up, with all being referred from out of province sources. All of these patients returned to their respective province of origin post treatment. Attempts were made to contact each patient post-GK for follow up via telephone, but were unsuccessful. The demographic data for those patients lost to follow up can be seen in Table 2 .

Table 1: Demographic Data for Patient Population and Three Year Follow-Up Group

\begin{tabular}{|c|c|c|}
\hline $\begin{array}{l}\text { Demographic } \\
\text { Category }\end{array}$ & $\begin{array}{l}\text { Total Patient Population } \\
\text { With Follow-Up }(n=15)\end{array}$ & $\begin{array}{l}\text { Three Year Follow- } \\
\text { Up Group }(n=11)\end{array}$ \\
\hline Mean Age & 14.2 (range: $7-18$ ) & 13.0 (range: $7-18$ ) \\
\hline Median Age & 15.0 & 15.0 \\
\hline \multicolumn{3}{|l|}{ Sex } \\
\hline Male & 6 & 4 \\
\hline Female & 9 & 7 \\
\hline $\begin{array}{l}\text { Average AVM Total } \\
\text { Volume }\left(\mathrm{cm}^{3}\right)\end{array}$ & 3.10 & 1.92 \\
\hline $\begin{array}{l}\text { Median AVM Total } \\
\text { Volume }\left(\mathrm{cm}^{3}\right)\end{array}$ & 2.40 & 2.20 \\
\hline $\begin{array}{l}\text { Average AVM } \\
\text { Diameter }(\mathrm{cm})\end{array}$ & 2.68 & 2.02 \\
\hline $\begin{array}{l}\text { Median AVM } \\
\text { Diameter }(\mathrm{cm})\end{array}$ & 0.96 & 0.86 \\
\hline Average SM Grade & 2.4 & 2.5 \\
\hline Median SM Grade & 2.0 & 3.0 \\
\hline Average Pollock Grade & 0.99 & 1.06 \\
\hline Median Pollock Grade & 0.84 & 0.90 \\
\hline $\begin{array}{l}\text { Average } 50 \% \text { Isodose } \\
\text { Line Dose (Gy) }\end{array}$ & 19.5 & 20.0 \\
\hline $\begin{array}{l}\text { Median } 50 \% \text { Isodose } \\
\text { Line Dose (Gy) }\end{array}$ & 20.0 & 20.0 \\
\hline $\begin{array}{c}\text { Total Number } \\
\text { Obliterated }\end{array}$ & 9 & 9 \\
\hline $\begin{array}{l}\text { Total Number of } \\
\text { Serious } \\
\text { Complications }\end{array}$ & 2 & 2 \\
\hline
\end{tabular}

$\mathrm{SM}=$ Spetzler-Martin Grade, AVM = Arteriovenous Malformation, $\mathrm{Gy}=$ Gray, $\mathrm{n}=$ number. Serious complications were defined as complications that had clinical manifestations and excluded minor conditions associated with frame placement, example pin site bleeding, edema, etc. 
Table 2: Characteristics of Four Patients Lost to Follow Up

\begin{tabular}{l|c|c|c|c|c}
\hline Sex & Age & Presentation & Location & SM Grade & Diameter of AVM (cm) \\
\hline $\mathrm{M}$ & 18 & Lt ICH & Lt Basal Ganglia & 3 & 2.80 \\
\hline $\mathrm{M}$ & 15 & H/A & Lt Occipital & 4 & 11.0 \\
\hline $\mathrm{M}$ & 14 & Motor tics & Lt Frontal & 1 & 0.85 \\
\hline $\mathrm{M}$ & 13 & ICH & Lt Frontal & 2 & 3.10 \\
\hline
\end{tabular}

$\mathrm{M}=$ Male, $\mathrm{ICH}=$ intracerebral hemorrhage, $\mathrm{H} / \mathrm{A}=$ head ache, $\mathrm{Lt}=$ left, $\mathrm{SM}=$ Spetzler-Martin, AVM= arteriovenous malformation.

Clinical presentation for the reviewed patients included: $\mathrm{ICH}$ or IVH in nine $(47.4 \%)$, headache in five $(26.3 \%)$, seizure in two $(10.5 \%)$, loss of consciousness in two $(10.5 \%)$, and motor tic in one $(5.3 \%)$. The locations of the AVMs were as follows: frontal lobe in seven $(36.8 \%)$, basal ganglia/thalamus in three $(15.7 \%)$, brainstem in three $(15.7 \%)$, temporal lobe in two $(10.5 \%)$, occipital lobe in two $(10.5 \%)$, parietal lobe in one $(5.3 \%)$, and cerebellum in one $(5.3 \%)$. Ten patients $(52.6 \%)$ had left sided AVMs, eight (42.1\%) had right sided AVMs, and one (5.3\%) had a midline AVM.

The mean diameter and volumes for the AVMs treated with GK were $2.68 \mathrm{~cm}$ (range: $0.85-3.50 \mathrm{~cm}$; median: $2.40 \mathrm{~cm}$ ) and $3.10 \mathrm{~cm}^{3}$ (range: $0.32-14.14 \mathrm{~cm}^{3}$; median: $0.96 \mathrm{~cm}^{3}$ ), respectively. The mean Spetzler-Martin ${ }^{13}$ and Pollock ${ }^{14,15}$ grades of the AVMs treated were 2.4 (range: 1-4; median: 2.0) and 0.99 (range: 0.28-3.63; median: 0.84), respectively.

Eleven of 15 patients $(73.3 \%)$ with follow-up data available had a minimum of three years follow-up post GK. We defined three years as a sufficient time period to allow for AVM response post-GK. Within this subpopulation of patients, the mean age was 13.0 years (range: 7-18 years; median: 15.0), with seven females $(63.6 \%)$. The mean diameter and volume of the AVMs treated were $2.02 \mathrm{~cm}$ (range: $1.00-3.50 \mathrm{~cm}$; median: 2.2 ) and $1.92 \mathrm{~cm}^{3}$ (range: $0.37-5.60 \mathrm{~cm}^{3}$; median: $0.86 \mathrm{~cm}^{3}$ ), respectively. The locations for these AVMs included: frontal lobe in three $(27.3 \%)$, brainstem in two $(18.2 \%)$, thalamic in two $(18.2 \%)$, temporal lobe in one $(9.1 \%)$, parietal lobe in one $(9.1 \%)$, occipital lobe in one $(9.1 \%)$, and cerebellum in one $(9.1 \%)$. Finally, the mean SpetzlerMartin and Pollock grades of these AVMs were 2.5 (range: 1-3; median: 3.0 ) and 1.06 (range: 0.28-3.63; median: 0.90), respectively. Demographic data for the three year follow-up group can be seen in Table 1.

\section{Treatment Characteristics}

The mean maximum dose was 39 Gy (range: $32-44$ Gy; median: 40 Gy). The mean marginal dose at the $50 \%$ isodose line was 19.5 Gy (range: 16-22 Gy; median: 20 Gy). We relied mainly on CTA and/or MRI scanning in treatment planning. All patients, however, did have a DSA as part of their initial diagnostic work up. Treatment planning and dose assignment were conducted by a neurosurgeon, radiation oncologist, and medical physicist.

One patient had two GK treatments for the same AVM at our facility. He was a 16 year male with a SM grade 3 left temporal AVM, presenting with a history of headaches. His initial treatment with GK was in 2004, displaying a good response and decrease AVM size over the course of three years. Given residual AVM on 36 month follow-up DSA, it was elected to repeat GK treatment to the remaining nidus. At 24 months post second GK, his AVM was confirmed to be obliterated by DSA.

\section{AVM Response to GK}

All of the patients with follow-up experience a decrease in AVM size post-GK. We defined AVM obliteration as the absence of an AVM on follow-up MRI or DSA. Nine of the 15 patients $(60.0 \%)$ with follow-up demonstrated obliteration of their AVMs post-GK. Of the remainingsix patients, all have displayed a decrease in AVM size on follow-up MRI post-GK, indicating some response to therapy. Follow-up for them is ongoing, with a current mean follow-up duration of 46.1 months (range: 13-118). The mean time to any radiological response post-GK was 15 months (range: 3-30 months).

Obliteration was confirmed with MRI and DSA in six patients, and MRI alone in three patients. In those patients who displayed AVM obliteration post-GK, the mean time to MRI resolution was 17.0 months (range: 6-27 months; median: 18.0 months). Arteriovenous malformation obliteration as confirmed via DSA occurred at a mean of 24 months (range: 12-30 months; median: 24.0 months) post-GK.

Within the three year follow-up group, 9 of $11(81.8 \%)$ experienced AVM obliteration on MRI or DSA. The remaining two patients have experienced a decrease in nidus size post-GK treatment, with follow-up ongoing. There was a trend between obliteration rates and the Spetzler-Martin and Pollock grades in the three year follow-up group, as seen in Tables 3 and 4.

Table 3 displays the Spetzler-Martin grades of 1, 2, and 3 with corresponding obliteration rates of $100 \%, 75 \%$, and $66 \%$ respectively. Similarly, Table 4 displays the number of patients with Pollock radiosurgery grades of less than 1,1 to 2 , and greater than 2 with obliteration rates of $85.7 \%, 0 \%$, and $0 \%$ respectively in the three year follow-up group. One patient had insufficient data to calculate an AVM volume for Pollock grade determination. They did however proceed onto AVM obliteration post-GK.

Of the three patients identified with previous embolization attempts prior to GK, one was lost to follow-up, and the remaining two displayed obliteration of their AVMs post-GK. The marginal dose at the $50 \%$ isodose line for these two cases were 18 and 20 Gy respectively.

\section{Complications}

Complications were reported in 7 of the 15 patients $(46.7 \%)$ with follow-up. We defined major complications as those that caused the patient clinical deficit enough to require either emergency room visit or non-scheduled imaging as an outpatient. Only two patients displayed major complications leading to post-GK 
Table 3: Spetzler-Martin Grades and Obliteration Rates for Three Year Follow-Up Group

\begin{tabular}{l|c|c}
\hline Spetzler-Martin Grade & Number of Patients & \% of AVMs Obliterated \\
\hline 1 & 1 & 100.0 \\
\hline 2 & 4 & 75.0 \\
\hline 3 & 6 & 66.6 \\
\hline 4 & 0 & N/A \\
\hline 5 & 0 & N/A \\
\hline
\end{tabular}

$\mathrm{AVM}=$ Arteriovenous Malformation, $\mathrm{N} / \mathrm{A}=$ Not applicable due to no patients in category.

edema. One developed transient hand weakness, the other only headache. Both resolved with a short course of dexamethasone without permanent complications.

The remaining complications described were minor and included: pin site edema/pain in four patients and transient headache/dizziness in one. These minor complications resolved after 48 hours post-GK. No hemorrhages occurred in any of the patients during the post-GK follow-up period.

\section{Discussion}

Radiosurgery for AVMs in the pediatric population is emerging as a first line treatment option for these lesions. Concerns with operative morbidity/mortality for microsurgical resection and endovascular embolization, especially in the developing brain, has fostered the interest in SRS as it is a non-invasive, and highly accurate radiation based treatment of AVMs. To date only a few studies focusing on the use of GK SRS for pediatric cerebral AVMs exist, with obliteration rates reported upwards of $82.7 \% .^{6}$ Complication rates with GK in pediatric AVMs have been variable in the literature, with the upper limit approaching $15 \%{ }^{9}$ The interpretation of these complication rates must occur with caution however, given the AVM hemorrhage rates are reported as complications post-GK in the majority of studies. These hemorrhage rates post-GK are within the values for the natural history of AVMs. Recent literature has indicated that the hemorrhage rate for AVMs post-GK is unchanged compared to natural history. ${ }^{16}$

Our institutional experience with AVMs was previously reported in $2011,{ }^{17}$ with obliteration rates at that time of $87.8 \%$ in a population consisting mainly of adult patients. The goal of this current study was to focus our results for GK of pediatric cerebral AVMs from November 2003 up to and including September 2014.

Table 4: Pollock Grades and Obliteration Rates for Three Year Follow-Up Group

\begin{tabular}{l|c|c}
\hline Pollock Grade & Number of Patients & \% of AVMs Obliterated \\
\hline$<1$ & 7 & 85.7 \\
\hline $1-2$ & 2 & 0 \\
\hline$>2$ & 1 & 0 \\
\hline N/A & 1 & 100 \\
\hline
\end{tabular}

$\mathrm{AVM}=$ Arteriovenous Malformation, N/A $=$ no Pollock grade due to insufficient data on the patients AVM volume.
Through our review, we were able to identify 19 pediatric patients treated with GK for AVMs within the defined time period. Four patients were lost to follow-up. The mean age of patients treated was 14.2 years (median 15.0 years), with the mean/median AVM diameter and volumes being $2.68 \mathrm{~cm} / 2.40 \mathrm{~cm}$ and $3.10 \mathrm{~cm}^{3} / 0.96 \mathrm{~cm}^{3}$ respectively. The mean/median SpetzlerMartin and Pollock grades of the treated AVMs were 2.4/2.0 and $0.99 / 0.84$ respectively. Of the 15 patients with follow-up (mean follow up of 62 months; median 51 months), 9 (60.0\%) were obliterated, with 9 of $11(81.8 \%)$ of those patients with a minimum of three years follow-up displaying obliteration. Major complications occurred in two patients. No AVM hemorrhage occurred during the follow-up period.

We were able to identify some important points from our results. First, our obliteration rate for those patients with three years of follow-up is approaching the upper limit of that reported in the literature to date. This likely stems from appropriate case selection, and maintaining unfractionated treatment plans for AVM diameters and volumes under $3 \mathrm{~cm}$ and $10 \mathrm{~cm}^{3}$ respectively. This is highlighted by our median AVM volume of $0.96 \mathrm{~cm}^{3}$. Furthermore, our success rate also reflects maintenance of marginal doses near $20 \mathrm{~Gy}$ (our mean was $19.5 \mathrm{~Gy}$; median $20 \mathrm{~Gy}$ ), as lower dosing has been specifically demonstrated in the pediatric population to lead to reduced obliteration rates. ${ }^{18}$ Given recent literature demonstrating ongoing obliteration in those patients observed beyond four and five years post-GK, ${ }^{19}$ it could be argued that, with longer follow-up, more of our patients would experience AVM obliteration. Second, our mean follow-up of 62 months for all patients is amongst the longest reported in the pediatric AVM GK series to date. The sustained obliteration in our patients during this long follow-up supports long term sustained obliteration of these malformations with GK. Third, only three patients treated at our institution had prior embolization, which has been linked to statistically significant reduced GK response and worse obliteration rates. ${ }^{20-22}$ Thus, our obliteration rate mostly reflects that of lesions presenting without prior treatment. For those two patients with previous embolization whom experience obliteration of their AVMs, there was no appreciable difference in their treatment parameters compared to the nonembolized patients. Fourth, low Spetzler-Martin ${ }^{13}$ and Pollock grades $^{14,15}$ seemed to improve the chance of obliteration, as seen in our previous study. ${ }^{17}$ Fifth, none of our pediatric patients treated with GK for their AVMs had hemorrhages during their follow-up period. This further emphasizes the literature evidence that GK treatment does not alter the hemorrhage rate during the period post-GK prior to AVM response. ${ }^{16}$ Finally, our major and permanent complication rates were low and within the range reported in the literature. This represents vigilance in maintaining tight conformity and minimizing the total $12 \mathrm{~Gy}$ volume, as this has been very well demonstrated to reduce the chance of complications in at risk individuals. ${ }^{23}$ Similarly, we avoided dosing above $25 \mathrm{~Gy}$ at the $50 \%$ isodose line, as this has been shown to increase post-GK complications without providing an increase in in-field obliteration rates. ${ }^{24,25}$

Despite these promising results, there are some significant limitations to our review. First, this is a retrospective single-center study with a small number of patients. Thus the results here cannot be generalized to all pediatric AVMs treated with GK and may not reflect those seen in larger series. Second, four patients were lost to follow-up. This represented $21.1 \%$ of the population treated. 
Despite our best efforts, contact with the patients was unsuccessful. It is possible that all of these patients failed treatment and may have had complications we are currently unaware of. Third, we defined obliteration of the AVM based on absence of the lesion on either MRI or DSA; this is not common convention in all radiosurgery centers. Obliteration via MRI was confirmed by both the interpreting neuroradiologist and treating neurosurgeon, looking for the presence of flow voids on $\mathrm{T} 2$ imaging and presence of contrast uptake consistent AVM presence on pre-operative studies. Furthermore, we have recently been utilizing perfusion based imaging to aid in determining perfusion asymmetries concerning for an otherwise occult persistent AVM, when such T2 and contrast based changes are absent. If there is any concern of persistent AVM based on MRI at our institution we then discuss with the patient (and family) the risk and benefits of formal angiographic confirmation. Thus, it can be argued, that those patients without DSA confirmation of obliteration may still have a small nidus present if interrogated by formal angiography. Currently, DSA is the gold standard in confirming AVM obliteration post-treatment. Recently, literature suggests MRI is sufficient ${ }^{11}$ and current series are starting to report obliteration rates in patients based on MRI only. ${ }^{8,16}$ Therefore, despite some controversy, we still believe in MRI confirmation of AVM obliteration post-GK. Fourth, although we have not seen long term significant radiation induced effects, given the young age of this population and potential years of life left to live, it is possible that they may suffer side effects related to GK in the future. Such potential long-term complications include: post-GK edema, radiation necrosis, and impairment of normal neuro-development. Similarly, the potential for radiation induced neoplasms, though rare, ${ }^{26}$ has been described during long term follow-up. ${ }^{27}$ The exact incidence of post-radiosurgery neoplasm formation is currently unknown, with recent literature confirming its very rare nature. ${ }^{26}$ Finally, only two patients presented with seizures. Thus, formal comments on seizure control post-GK for pediatric AVMs cannot be made at this time.

\section{Conclusions}

GK radiosurgery for pediatric AVMs affords a high obliteration rate at three years, with low permanent complication rates during early follow-up.

\section{Disclosures}

The authors do not have anything to disclose.

\section{REFERENCES}

1. Niazi TN, Klimo P, Anderson RCE, Raffel C. Diagnosis and management of arteriovenous malformations in children. Neursurg Clin N Am. 2010;21:443-56.

2. Kondziolka D, Humphreys RP, Haffman HJ, Hendrick EB, Drake J. Arteriovenous malformations of the brain in children: a forty year experience. Can J Neurol Sci. 1992;19:40-5.

3. Foy AB, Wetjen N, Pollock BE. Stereotactic radiosurgery for pediatric arteriovenous malformations. Neurosurg Clin N Am. 2010;21:457-61

4. Rubin D, Santillan A, Greenfield JP, Souweidane M, Riina HA. Surgical management of pediatric cerebral arteriovenous malformations. Childs Nerv Syst. 2010;26:1337-44.

5. Frizzel RT, Fisher WS 3rd. Cure, morbidity, mortality associated with embolization of brain arteriovenous malformations: a review of 1246 patients in 32 series over a 35-year period. Neurosurgery. 1995;37:1031-9.
6. Dinca EB, De Lacy P, Yianni J, et al. Gamma knife surgery for pediatric arteriovenous malformations: a 25 -year retrospective study. J Neurosurg Pediatrics. 2012;10:445-50.

7. Pan DHC, Kuo YH, Guo WY, et al. Gamma knife surgery for cerebral arteriovenous malformations in children: a 13-year experience. J Neurosurg Pediatrics. 2008;1:296-304.

8. Kano H, Konziolka D, Flickinger JC, et al. Stereotactic radiosurgery for arteriovenous malformations, part 2: management of pediatric patients. J Neurosurg Pediatrics. 2012;9:1-10.

9. Borcek AO, Emmez H, Akkan KM, et al. Gamma knife radiosurgery for arteriovenous malformations in pediatric patients. Childs Nerv Syst. 2014;30:1485-92.

10. Tamura N, Hayashi M, Chernov M, et al. Outcome after gamma knife surgery for intracranial arteriovenous malformations in children. J Neurosurg. 2012;117(Suppl):150-7.

11. Zadeh G, Andrade-Souza YM, Tsao MN, et al. Pediatric arteriovenous malformation: University of Toronto experience using stereotactic radiosurgery. Childs Nerv Syst. 2007;23(2):195-9.

12. Pollock BE, Kondziolka D, Flickinger JC, et al. Magnetic resonance imaging: an accurate method to evaluate artiovenous malformations after stereotactic radiosurgery. J Neurosurg. 1996;85: 1044-9.

13. Spetzler RF, Martin NA. A proposed grading system for arteriovenous malformations. J Neurosurg. 1986;65:476-83.

14. Pollock BE, Flickinger JC. A proposed radiosurgery-based grading system for arteriovenous malformations. J Neurosurg. 2002;96:70-85

15. Pollock BE, Flickinger JC. Modification of the radiosurgery-based arteriovenous malformation grading system. Neurosurgery. 2008;63:239-43

16. Pollock BE, Flickinger JC, Lunsford LD. Hemorrhage risk after stereotactic radiosurgery of cerebral arteriovenous malformations. Neurosurgery. 1996;38:652-9.

17. Zeiler FA, McDonald PJ, Kaufmann A, Fewer D, Butler J, Schroeder G, West M. Gamma knife for cerebral arteriovenous malformations at as single center. Can J Neurol Sci. 2011;38:851-7.

18. Potts MB, Sheth SA, Louie J, et al. Stereotactic radiosurgery at a low marginal dose for the treatment of pediatric arteriovenous malformations: obliteration, complications and functional outcomes. J Neurosurg Pediatrics. 2014;14:1-11.

19. Kano H, Kondziolka D, Flickinger JC, et al. Stereotactic radiosurgery for arteriovenous malformations, part 3: outcome predictors and risks after repeat radiosurgery. J Neurosurg.. 2012;116:21-32.

20. Kano H, Konziolka D, Flickinger JC, et al. Stereotactic radiosurgery for arteriovenous malformations after embolization: a casecontrol study. J Neurosurg. 2012;117:265-75.

21. Andrade-Souza YM, Ramani M, Scora D, et al. Embolization before radiosurgery reduces the obliteration rate of arteriovenous malformations. Neurosurgery. 2007;60:443-52.

22. Back AG, Vollmer D, Zeck O, et al. Retrospective analysis of unstaged and staged Gamma Knife surgery with and without preceding embolization for the treatment of arteriovenous malformations. J Neurosurg. 2008;109(Suppl):57-64.

23. Flickinger JC, Kondziolka D, Lunsford LD, et al. Development of a model to predict permanent symptomatic postradiosurgery injury for arteriovenous malformation patients. Int $\mathrm{J}$ Radiat Oncol Biol Phys. 2000;46:1143-8.

24. Flickinger JC, Kondziolka D, Maitz AH, et al. An analysis of the dose-response for arteriovenous malformation radiosurgery and other factors affecting obliteration. Radiother Oncol. 2002; 63:347-54

25. Flickinger JC, Pollock BE, Kondziolka D, et al. A dose-response analysis of arteriovenous malformation obliteration after radiosurgery. Int J Radiat Oncol Biol Phys. 1996;36:873-9.

26. Rowe J, Grainger A, Walton L, Silcocks P, Radatz M, Kemeny A. Risk of malignancy after gamma knife stereotactic radiosurgery. Neurosurgery. 2007;60:60-5.

27. Shamisa A, Bance M, Nag S, et al. Glioblastoma multiforme occurring in a patient treated with gamma knife surgery: case report and review of the literature. J Neurosurg. 2013;119(Suppl): $816-21$. 